\title{
The Predictive Relationship between Earthquake Intensity and Tweets Rate for Real-
} Time Ground Motion Estimation

\author{
Yelena Kropivnitskaya ${ }^{1}$, Kristy F. Tiampo ${ }^{1,2}$, Jinhui Qin ${ }^{3}$ \\ and Michael A. Bauer ${ }^{4}$ \\ ${ }^{1}$ Department of Earth Sciences, Western University, London, Canada \\ ${ }^{2}$ CIRES and Department of Geological Sciences, University of Colorado, Boulder, CO, USA \\ ${ }^{3}$ SHARCNET, Western University, London, Canada \\ ${ }^{4}$ Department of Computer Science, Western University, London, Canada \\ ykropivn@uwo.ca,kristy.tiampo@colorado.edu,jqin5@uwo.ca,bauer@uwo.ca \\ Corresponding author: Yelena Kropivnitskaya \\ Department of Earth Sciences, \\ Western University, \\ Biological \& Geological Sciences Building, Room 1020 \\ 1151 Richmond Street N. \\ London, Ontario, Canada, N6A 5B7 \\ Phone: +1 2262387070 \\ Email: ykropivn@uwo.ca
}

\section{Abstract}

The standard measure for evaluation of the immediate effects of an earthquake on people and man-made structures is intensity. Intensity estimates are widely used for emergency response,

21 loss estimation and distribution of public information after earthquake occurrence. Intensity

22 measures are designed to standardize the measurements of seismic effect and their subsequent

23 evaluation and response (Brazee, 1976; Wood and Neumann, 1931). Modern intensity 
assessment procedures process a variety of information sources. Those sources are primarily from two main categories: physical sensors (seismographs and accelerometers) and social sensors (witnesses reports). Acquiring new data sources in the second category can help to speed up the existing procedures for intensity calculations and improve the accuracy of those assessments in a more timely fashion. One potentially important data source in this category is the widespread micro-blogging platform Twitter, ranked ninth worldwide as of January 2016 by number of active users, $\sim 320$ million (Twitter, 2016). In our previous studies, empirical relationships between tweet rate and observed Modified Mercalli Intensity (MMI) were developed using data from the M6.0 South Napa, CA earthquake (Napa earthquake) that occurred on August 24, 2014 (Kropivnitskaya et al., 2016). These relationships allow us to stream data from social sensors, supplementing data from other sensors to produce more accurate real-time intensity maps. The streaming application implementation is based on IBM InfoSphere Streams, a cloud platform for real-time analytics on big data (IBM, 2014). These relationships could potentially decrease latency in the intensity calculations for future earthquakes in California and other places around the world. However, there is a strong need for their validation and calibration in regions other than California. In this study, we validate empirical relationships between tweet rate and observed MMI using new datasets from earthquakes that occurred in California, Japan and Chile during the period March-April 2014. The statistical complexity of the validation test and calibration process is complicated by the fact that the Twitter data stream is limited for open public access, reducing the number of available tweets. In addition, in this analysis only spatially limited positive tweets (marked as a tweet about earthquake) are incorporated into the analysis, further limiting the data set and restricting our study to a historical data set. In this work, the predictive relationship for California is recalibrated slightly and a new set of relationships is estimated for the Japan and Chile. 


\section{Introduction}

49 Earthquake intensity is a location-specific characteristic of the extent and amount of seismic

50 damage that depends not only on the magnitude of the earthquake but also on the distance from

51 the earthquake epicenter to the site of interest and the geological features of the surrounding area.

52 The first earthquake intensity classification was designed and used by Italian scientist

53 Schiantarelli in the 1780 s. However, the first modern intensity scale was created in 1828 by

54 P.N.G. Egen. The first widely adopted intensity scale, the Rossi-Forel scale, was introduced to

55 the scientific community in the late 19th century. Since then, numerous intensity scales have

56 been developed and are used in different parts of the world (Hough, 2007).

57 The traditional understanding of earthquake intensity is based on estimates of infrastructure damage at the specific site of interest estimated from the subjective perception of professional observers and/or volunteers who witnessed the earthquake and its consequences. For this 60 purpose, specially designed questionnaires are designed and at particular locations. A

61 successful example of the modern implementation of this approach is the Did You Feel It?

62 program created by United States Geological Survey (USGS) that collects information from

63 people who experience an earthquake and volunteer to share their observations online to create 64 Community Internet Intensity Maps (CIIM) with observations and extent of damage (Wald et al., 65 1999).

66 In addition to the intensity evaluation method based on human observations, another approach is 67 to determine intensity from the peak ground motion, either velocity or acceleration, at a station 68 near the site of interest. Empirical relationships then are employed to calculate intensity level 69 (Worden et al., 2012). Results can be obtained much faster than results obtained from the 70 observation-based analysis. A successful realization of this method is the ShakeMap application, 71 also developed by the USGS (Wald et al., 2006). 
72 The intensity evaluation approaches can be divided into two main categories according to the

73 input information source type, above. The first evaluation category employs social sensor data

74 from people who witness the consequences of the earthquake. The second utilizes data from

75 physical sensors, such as seismometers and accelerometers to estimate intensity. Although the

76 first method historically estimated intensity at a much slower rate than that of physical sensors,

77 today electronic questionnaires and observers' reports can be supplemented with auxiliary online

78 data sources from social networks, where people also share their observations after an

79 earthquake. Here we access data from the online social networking service Twitter. Twitter

80 enables users to send and read short 140-character messages called "tweets". Registered users

81 can read and post tweets while unregistered users can only read those tweets. Users can access

82 Twitter through the website interface, SMS or a mobile device application that is the true source

83 of the real-time nature of tweets (Twitter, 2016). Twitter data is immediately available in a data

84 stream, which can be mined using stream mining techniques (Schonfeld, 2009). In this study we

85 work with data following the stream model. In this model, data arrive at high speed and data

86 mining algorithms must be able to predict intensity level in real-time and under strict constraints

87 of space and time (Bifet et al., 2010).

88 Previous studies have shown the potential of Twitter data for earthquake detection (Earle et al., 89 2010, 2011; Sakaki, 2010; Crooks, 2012; Burks et al., 2014) and intensity estimation 90 (Kropivnitskaya et al., 2016). Kropivnitskaya et al. (2016) created four empirical predictive 91 relationships (linear, two-segment linear, three-segment linear, exponential) that link the positive

92 tweet rates in the first ten minutes following the earthquake with the instrumental intensity level 93 in MMI scale units from a regression analysis of data from physical and social sensors during the 94 Napa earthquake. Figure 1 shows the ratio between the combined data (instrumental and Twitter) 
95 and the MMI intensity values recorded from the USGS in the Napa region. The ratio between

96 estimated and actual intensity is relatively low for this particular earthquake. The proposed joint

97 processing technique using social and physical data demonstrates a significant potential for near

98 real-time predictive streaming applications. However, the developed empirical relationships

99 between earthquake intensity and tweet rates still need to be validated for all of California and 100 other seismically active regions of the world and, if necessary, they need to be spatially 101 calibrated.

102 The statistical complexity of validating and calibrating the model is complicated by the fact that 103 Twitter data stream is limited for open public access. The basic levels allow only up to $1 \%$ of the 104 total tweets volume to be streamed (Twitter, 2016). For our purposes only spatially limited 105 positive tweets (tweets about earthquake) are used, so the rate limitations are critical and 106 historical data are used in our application instead of a real data stream. The relationships are 107 validated and calibrated for three regions: California, Chile and Japan. The degree of social 108 media engagement across these countries is relatively high. The proportion of each country's 109 population that had a Twitter account as of February 2012 is $36 \%$ in the USA, 24\% in Japan and $11033 \%$ in Chile (Dawson, 2012). Therefore, potential for the success of Twitter streaming 111 applications in these regions is high. In the next section we discuss the social and physical sensor 112 data used in this study. The following section contains the details of the validation procedure 113 followed by an explanation of and results for the calibration process for California, Japan and 114 Chile regions. Finally, concluding remarks are provided.

\section{Data preparation}

116 In order to validate whether the numerical results quantifying hypothesized relationships 117 between logarithmic tweet rates following ten minutes after an earthquake and earthquake 
118 intensity on MMI scale, obtained from Kropivnitskaya et al. (2016), can be used for other 119 earthquakes in California and in other regions around the world, we selected independent events 120 for testing purposes listed in Table 1. The magnitude scale used in Table 1 is moment magnitude.

121 The moment magnitude is a static measure of earthquake size that strongly depends on stress 122 drop. It does not directly quantify the radiated energy and, as a result, there are limits to its 123 ability to on reliably estimate earthquake size (Hanks and Johnston, 1992). However, these 124 considerations do not impact the current analysis as earthquake size is given here only for 125 reference purposes and not used as predictive attribute in the model. The events listed in the 126 Table 1 are shown in Figure 2a (California), Figure 2b (Chile) and Figure 2c (Japan). None of 127 these events was included in the original analysis of Kropivnitskaya et al. (2016).

128 The selection of seismic events used in this validation is dictated by two constraints. The first is 129 to ensure that there is a large amount of freely available Twitter data. Gathering information 130 from social media feeds is, in essence, a web-mining process (Kosala and Blockeel, 2000; Sakaki 131 et al., 2010). It entails three operations: Extracting data from the data providers (in this case 132 Twitter) via application programming interfaces (APIs); parsing, integrating, and storing these 133 data in a resident database; and then analyzing these data to extract information of interest. 134 However, currently available Twitter tools offer limited capabilities for information gathering 135 procedures (Twitter, 2016). As a result, we used an archived historical dataset of Twitter records 136 from March-April 2014 (see Data and Resources Section). The second limitation is related to the 137 lack of geotagged data within available Twitter data sets. We selected seismic events that both 138 showed a spike in the amount of positive tweets within ten minutes following the earthquake and 139 where at least fourteen of those tweets were geotagged (the minimum number of tweets in the 140 models (Kropivnitskaya et al., 2016)). The geotagged tweets contain the current user location 141 indicator at the time of tweeting and can be directly used in the location-specific intensity 
142 estimation algorithms. However, Graham et al. (2014) showed that only $0.7 \%$ tweets are 143 geotagged among 19.6 million tweets. In this case, other tweets that do not have a direct specific 144 location reference, but contain a link to specific cities can be used. The percentage of geotagging 145 in this case is between $2 \%$ and 5\% (Severo et al., 2015). A geotag can also be obtained from a 146 field in the user account description (7.5\% of profiles contain latitude and longitude values, $57 \%$ 147 include a named location, 20.4\% referenced information that can be used to identify a country, 148 while $15.1 \%$ provided humorous or non-spatial information (Takhteyev et al., 2012)). In the 149 approach used by Kropivnitskaya et al. (2016), all three types of geotagged technics were used 150 and the same logic has been implemented here. A text-based geolocation algorithm has been 151 improved by employing a location database extension for California, Japan and Chile. In 152 updating the location database, the complete, shortened or abbreviated names are included for 153 any settlements with a population of more than five thousand people in a $200 \mathrm{~km}$ radius of the 154 epicenter of the earthquakes listed in Table 1 (see Figure 2).

After building a data set for each event that is limited in time and space, we generated a tweet157 frequency time series with one second time bins and normalized to number of tweets per minute. 158 Note that in the current study we did not use strong motion records and did not calculate 159 intensity level using empirical relationships. Instead, for each point from the Twitter data set we 160 assigned an MMI intensity value from the instrumental intensity database of the USGS National

161 Earthquake Information Center (see Data and Resources Section) corresponding to the same or 162 closest latitude-longitude location (for closest location selection the smallest distance between 163 the points is estimated). For California we selected the M6.8 Ferndale, CA earthquake (March 164 10, 2014) and the M5.1 La Habra, CA earthquake (March 29, 2014) (Figure 2a) (Kropivnitskaya 165 et al., 2016). 


\section{Relationship Validation}

Earlier relationships between positive tweet rates and observed MMI were developed only using data from the Napa earthquake (Kropivnitskaya et. al, 2016). In order to employ them to supplement data from physical sensors for more accurate real-time intensity maps production, the relationships have to be validated for other areas of California and other tectonic regions worldwide. The validation process analyzes the goodness of fit of the regression for Napa earthquake, determining whether the regression residuals are random, and checking whether the model's predictive performance deteriorates substantially when applied to data for the Ferndale and La Habra earthquakes, events in California not used in the original model derivation. Both events are not large enough to validate empirical relationships at intensity levels higher than VI. As a result, the three-segment model is excluded from the validation test.

Both earthquakes' datasets show that the positive tweets rate increases slower than that predicted by the empirical relationships for the Napa earthquake derived in Kropivnitskaya et al. (2016).

The residuals for both events are shown with whisker diagrams for different models in Figure 3, and display the distribution of the residuals based on a five number summary: minimum, first quartile, median, third quartile, and maximum. The quartiles of the present data values are the three points that divide the data set into four equal groups, each group comprising a quarter of the data. The first quartile is defined as the middle number between the smallest number and the median of the data set. The median of the data is a second quartile. The third quartile is the middle value between the median and the highest value of the data set. The Interquartile Range (IQR) is used here to characterize outliers that skew the data.

Despite the fact that the La Habra data (Figure 3b) contains significantly more outliers in the residuals than the Ferndale data (Figure 3a), the mean residuals for every model for the La Habra 
189 event are much closer to zero (the linear model mean residual is 0.37 MMI units; the exponential 190 model mean residual is -0.25 MMI units; the two-segment model mean residual is $0.28 \mathrm{MMI}$ 191 units) than for Ferndale event (the linear model mean residual is 1.28 MMI units; the exponential 192 model mean residual is 0.98 MMI units; the two-segment model mean residual is $1.57 \mathrm{MMI}$ 193 units).

194 A visual examination of the residuals has an advantage over numerical model validation methods 195 because it illustrates the complex aspects of the relationship between the model and the new data. 196 Figure 4 shows the residuals from the fitted models. The residuals are not randomly distributed 197 around zero, indicating that the linear assumption may be not reasonable (Figure 4b). However, 198 even for the exponential model case (Figure 4a), the residuals are not distributed normally 199 around zero. In this case, the variances of the error terms at each MMI level are not equal due to 200 the different number of twitter responses at each level. Moreover, some of the residuals stand out 201 from the basic pattern, confirming there are outliers in the data as indicated by whisker diagrams 202 (Figure ). These data points have to be excluded from the calibration procedure detailed below.

203 Intensity attenuates with distance from the epicenter of an earthquake and intensity prediction 204 equations usually rely on some distance metric. For example, some models use epicentral 205 distance (Bakun and Wentworth, 1997), or closest distance to rupture, or some variant that 206 considers extended fault sources, such as the Joyner-Boore distance (Joyner and Boore, 1993). 207 For small magnitude earthquakes, where an earthquake can be approximated by a point source, 208 the difference between point and extended source distance metrics can be minimal. However, at 209 larger magnitudes where source finiteness can be significant, prediction equations which use 210 point source distance metrics may not be applicable (Cua et al., 2010). In this evaluation, we 211 consider the epicentral distance, a point-source distance metric, as a potential predictor for the 
212 equations of Kropivnitskaya et al. (2016). The anticipated influence of the distance metric on the

213 predictive equations is based on the assumption that number of positive tweets and tweet rates

214 are expected to attenuate with distance from the epicenter. As a result, the behaviour of the

215 ground motion components may vary with epicentral distance and result in a variation in the type

216 and/or magnitude of structural damage. To assess this possibility, we plotted residuals versus

217 epicentral distance (Figure 4a, c, e). Note that these plots do not exhibit a systematic structure

218 and, as a result, the form of the function cannot be improved using that predictor.

220 To check for temporal variation in the data, the residuals also are plotted versus time (Figure b,

$221 \mathrm{~d}, \mathrm{e})$. At each minute, the intensity map is updated according to new the values received during

222 the last minute. However, at the same time all values obtained earlier remain on the map and are

223 incorporated into the overall intensity representation. Results show that the residuals plotted

224 versus time do not show any drift in the errors and appear to behave randomly.

Both sets of residual plots do record the delay from zero distance and zero time for the Ferndale earthquake, an offshore event that occurred 78 kilometers off the coast. The cumulative error over the ten minute interval is shown on Figure. The maximum error for the Ferndale earthquake 229 registered at the third minute, the minimum error occurred at the tenth minute. For the La Habra event, the maximum error registered at the first and seventh minutes while the minimum error occurred at the fifth and tenth minute. Results suggest that the original model of Kropivnitskaya et al. (2016) does not fit the validation dataset as well as the data from the Napa Valley earthquake it was developed from and a more complete calibration process for the California region is warranted as more data becomes available. 
236 Figure shows the data for Chile and Japan earthquakes from Table 1 plotted with the prediction

237 models of Kropivnitskaya et al. (2016). The data distribution follows the same pattern as the

238 models, but it is clear that the models have to be calibrated and shifted to the left to represent the

239 data relationships better. One of the Chile earthquakes has a significantly higher amount of 240 tweets after an earthquake (Figure a, upward triangles). Noting that all earthquakes generally 241 show common characteristics, one possible reason could be related to the fact that this 242 earthquake happened the day after the M6.7 event that occurred $64 \mathrm{~km}$ WNW of Iquique on 243 March 16, 2014. People were likely alert and their reaction was stronger. The data from Japan 244 does not allow for validation of the empirical relationships at an intensity level higher than V. As 245 a result, the three-segment and two-segment models are excluded from the calibration. Observed 246 data for the Chile region represent the intensity levels up to VI, therefore three-segment model is 247 not taken into consideration.

\section{$248 \quad 4$ Calibration of Existing Relationships}

249 In validating the earlier relationship in the previous step, discrepancies were noted in the spatial 250 variation of intensity, resulting in the need for spatial model calibration. This calibration task 251 involves systematic adjustment of model parameter estimates so that the model outputs more 252 accurately reflect external benchmarks (Thompson, 2012). The forward problem that describes 253 the relation between the logarithmic tweets rate and intensity predictions may be represented 254 with an equation in the following form:

$$
M M I=f(\theta)+e,
$$

256 Where,

MMI is the aggregated instrumental intensity level observed, 
$\theta \quad$ is the vector of the tweet rates observed,

exponential, 2-segment, 3-segment),

262 predicted values of intensity (2). Here

$$
e=e_{o}+e_{m}
$$

264 where $e_{o}$ accounts for measurement error in the observations, and $\mathrm{e}_{\mathrm{m}}$ is the model error.

265 The calibration here is an inverse procedure. An inverse estimator $C$ that connects the 266 observations MMI to "good" estimates $g$ of the parameters of interest:

$$
g=C[f(\theta)+e]=\min \sum[M M I-f(\theta)]^{2}
$$

268 We used known data in the observed relationship between the dependent variable MMI and 269 independent variable logarithmic tweets rate to estimate values for regions other than Napa 270 Valley using new observations from the earthquakes listed in the Table 1. Linear regression is 271 used to produce new regression coefficients for each region. We regress instrumental MMI 272 against the logarithmic mean of the number of tweets per minute to obtain new predictive 273 equations (Figure ) within a legitimate range of values for each model (see Table 2). We also 274 regress the average ground-motion values for specified MMI levels to approximately follow the 275 appropriate trend instead of producing a relationship that is overly influenced by the greater 276 statistical volume of data at lower intensities. We applied a least squares solution with 95\% 277 confidence bounds for each model. 
279 For the California region the lowest root-mean-square (RMS) of 0.0029 MMI units is observed

280 for the two-segment model. For the Napa earthquake (Kropivnitskaya et al., 2016) the lowest 281 error was achieved with the three segment model, excluded from validation here. The 282 exponential model demonstrates the RMS error of 0.0035 MMI units. For the Japanese data the 283 difference between the RMS error for the linear and exponential models also is not significant 284 (0.0207 vs. 0.0186). This may be explained by the use of the mid-valued intensity data in the 285 regression (III - V). For lower intensity levels (I-III), the difference will be more significant and 286 for intensity levels higher than V it is less significant (see Figure b). For the Chile earthquakes, 287 the lowest RMS error of 0.0143 MMI units is observed for the linear model, which is 0.0002 288 units lower than for exponential model.

Because the RMS error cannot determine whether the model estimates and predictions are

291 biased, we also assessed the residual plots (Figure ). The residuals between the predicted and 292 observed data are shown in Figure a for each model in the California region and demonstrate 293 normality in every case. The residual distribution for Japan also is nearly normal for both 294 calibrated models. The distribution of the Chile data residuals is skewed to the left for the two295 segment model and skewed to the right for the linear and exponential models. The condition that 296 the error terms are normally distributed is not met in that case.

\section{Conclusions}

298 Incorporation of social sensor data with traditional data sources using advanced computational 299 processing methods can provide more complete and accurate coverage of damage and loss for 300 rapid earthquake response. The prediction equations obtained in this work could be used for real301 time seismic hazard mapping and emergency management purposes in California, Japan and 
302 Chile using real-time data streaming concept of Twitter data. However, because our previous

303 work showed a higher level of uncertainty resulting from the use of Twitter data alone when

304 compared to results streamed jointly with instrumental intensity, we propose to use the empirical

305 equation for Twitter data together with the data from physical sensors as presented in

306 Kropivnitskaya et al. (2016).

307

308 The twitter stream processing here uses data recorded within the ten minutes following an 309 earthquake. We confirm our earlier hypothesis that the logarithmic number of tweets can be used 310 as a proxy for shaking intensity not just in the California region, but also in other regions with 311 large numbers of Twitter users, such as Japan and Chile. However, for actual real-time 312 implementations, there is a need to remember that the calibrated relationships presented in this 313 paper are constrained by the number of tweets in the historical dataset. Unlimited access to the 314 Twitter data stream would allow for new, improved calibration of the regional relationships from 315 around the world. In many areas, the importance of this additional data source could be very 316 significant, due to the complete or partial lack of traditional, instrumental data sources as a result 317 of the high cost of their installation and ongoing operation. 
319 Data and Resources

320 Instrumental intensity data used in this study is obtained from USGS National Earthquake

321 Information Center at http://earthquake.usgs.gov/earthquakes/search/ (last accessed on June 20,

322 2016). Archived historical dataset of Twitter records from March-April 2014 (downloaded from

323 https://archive.org/details/twitterstream) were used in this study. Figures were created using

324 GMT (Wessel and Smith, 1991) and Matlab plotting software.

\section{Acknowledgments}

326 The research of KFT and YK was made possible by a MITACS Accelerate grant and an NSERC

327 Discovery Grant and is the result of collaboration between the Western University

328 Computational Laboratory for Fault System Modeling, Analysis, and Data Assimilation and

329 SHARCNET, a high performance computing consortium of Canadian academic institutions.. 


\section{References}

Bifet, A., Holmes, G., Kirkby, R., and Pfahringer, B., 2010. MOA: Massive online analysis. Journal of Machine Learning Research (JMLR), pp.1601-1604.

Bakun, W. H. Wentworth, C. M., 1997. Estimating earthquake location and magnitude from seismic intensity data, Bull. Seism. Soc. Am. 87, pp. 1502- 1521.

Brazee, Rutlage J., August 1976: Final Report: An Analysis of Earthquake Intensities with Respect to Attenuation, Magnitude, and Rate of Recurrence (Revised Edition), NOAA Tech. Memorandum EDS NGSDC-2, NOAA/National Geophysical Data Center, Boulder, Colorado, p. 53.

Burks, L., Miller, M. \& Zadeh, R., 2014. Rapid estimate of ground shaking intensity by combining simple earthquake characteristics with tweets. s.1., Tenth U.S. National Conference on Earthquake Engineering Frontiers of Earthquake Engineering.

Center for International Earth Science Information Network - CIESIN - Columbia University, and Centro Internacional de Agricultura Tropical - CIAT. 2005. Gridded Population of the World, Version 3 (GPWv3): Population Density Grid. Palisades, NY: NASA Socioeconomic Data and Applications Center (SEDAC). http://dx.doi.org/10.7927/H4XK8CG2. Accessed 10/10/2015

Crooks, A., Croitoru, A., Stefanidis, A. \& Radzikowski, J., 2012. Earthquake: Twitter as a Distributed Sensor System. Transactions in GIS , 17(1), pp. 124-147.

Cua, G., D. J. Wald, T. I. Allen, D. Garcia, C. B. Worden, M. Gerstenberger, K. Lin, K. Marano. 2010. GEM1 "Best Practices" for Using Macroseismic Intensity and Ground Motion Intensity Conversion Equations for Hazard and Loss Models in GEM1. GEM Foundation: GEM Technical Report, 44 p.

Dawson, R., 2012 Which countries have the most Twitter users per capita? [Online] Available at: http://rossdawsonblog.com/weblog/archives/2012/02/which-countries-have-the-mosttwitter-users-per-capita.html/[Accessed 2016].

Earle, P., Bowden, D. \& Guy, M., 2011. Twitter earthquake detection: earthquake monitoring in a social world. Annals of Geophysics, 54(6), pp. 708-715.

Earle, P., Guy M., Buckmaster R., Ostrum C., Horvath S., Vaughan A., 2010. OMG Earthquake! Can Twitter Improve Earthquake Response?. Seismological Research Letters, 81(2), pp. 246-251.

Graham, M., Hale, S. A., \& Gaffney, D. (2014). Where in the World Are You? Geolocation and Language Identification in Twitter. The Professional Geographer, 66(4), 568-578. http://doi.org/10.1080/00330124.2014.907699

Hanks, T.C., and Johnston, A.C., 1992, Common features of the excitation and propagation of strong ground motion for North American earthquakes: Seismological Society of America Bulletin, v. 82, p. 1-23.

Hough, S.E. (2007). Richter's scale: measure of an earthquake, measure of a man. Princeton University Press. p. 121. ISBN 978-0-691-12807-8.

IBM, n.d. IBM, 2014. IBM Knowledge Center. [Online] Available at: http://www01.ibm.com/support/knowledgecenter/[Accessed 2015]. 
Joyner, W.B. and D.M. Boore, 1993. Methods for regression analysis of strong-motion data, Bull. Seism. Soc. Am. 83, 469-487.

Kosala, R., and H. Blockeel, 2000, Web Mining Research: A Survey, SIGKDD Explorations 2, $1-15$.

Kropivnitskaya, Y., Tiampo, K., Qin, J., \& Bauer, M. (2016). Real-Time Earthquake Intensity Estimation Using Streaming Data Analysis of Social and Physical Sensors. Pure and Applied Geophysics, accepted with minor revisions.

Sakaki, T., Okazaki, M. \& Matsuo, Y., 2010. Earthquake Shakes Twitter Users: Real-Time Event Detection by Social Sensors. Raleigh, NC, World Wide Web Conference (WWW).

Schonfeld E., 2009. Mining the thought stream. TechCrunch Weblog Article, http://techcrunch.com/2009/02/15/mining-the-thought-stream/.

Severo, M., Giraud, T., \& Pecout, H. (2015). Twitter data for urban policy making: an analysis on four European cities. In C. Levallois (Ed.), Handbook of Twitter for Research. EMLYON

Takhteyev Y., Wellman B., Gruzd A., 2012. Geography of Twitter Networks, Social Networks, Volume 34, Issue 1, January 2012, pages 73-81

Twitter, 2016. The Twitter Platform Documentation. [Online] Available at: https://dev.twitter.com/overview/documentation [Accessed 2016].

United States Geological Survey, 2015a. Earthquake Facts and Statistics. [Online] Available at: http://earthquake.usgs.gov/earthquakes/eqarchives/year/eqstats.php [Accessed 2015a].

United States Geological Survey, n.d. The Modified Mercalli Intensity Scale. [Online] Available at: http://earthquake.usgs.gov/learn/topics/mercalli.php [Accessed 2015b].

Wald, D.J., Quitariano, V., Heaton, T.H., Kanamori, H., Scrivner C.W., and Worden, c.B. (1999). "Trinet ShakeMaps: rapid generation of peak ground motion and intensity maps for earthquakes in Southern California," Earthquake Spectra, 15, 537-555.

Wald, D., Worden, B., Quitoriano, V. \& Pankow, K., 2006. ShakeMap Manual: Technical Manual, Users Guide, and Software Guide, Boulder: United States Geological Survey.

Wessel, P. and W. H. F. Smith, Free software helps map and display data, EOS Trans. AGU, 72, $441,1991$.

Wood, H. O. and F. Neumann, Dec. 1931: "Modified Mercalli Intensity Scale of 1931," Bulletin of the Seismological Society of America, v. 21, No. 4, p. 277-283. Worden, C.B., Gerstenberger, M.C., Rhoades, D.A., and Wald, D.J. (2012). Probabilistic relationships between ground-motion parameters and Modified Mercalli intensity in California. Bull. Seism. Soc. Am. 102:1, 204-221. doi: 10.1785/0120110156. 


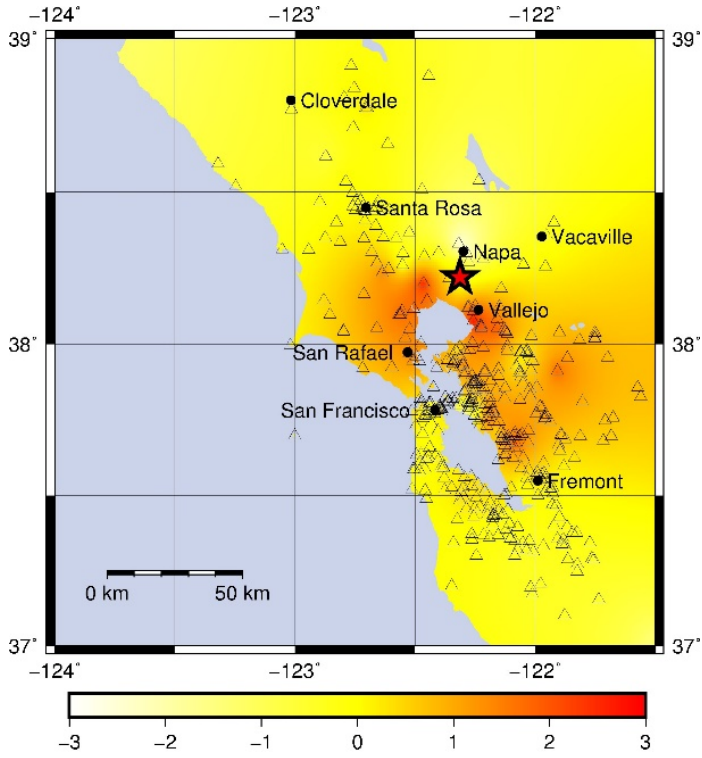

a).

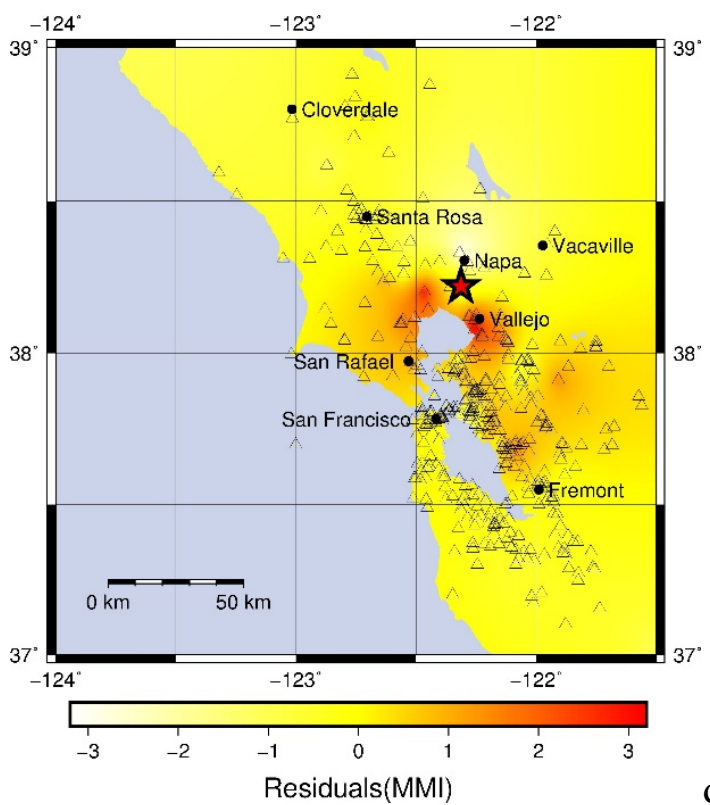

c).

408 model.

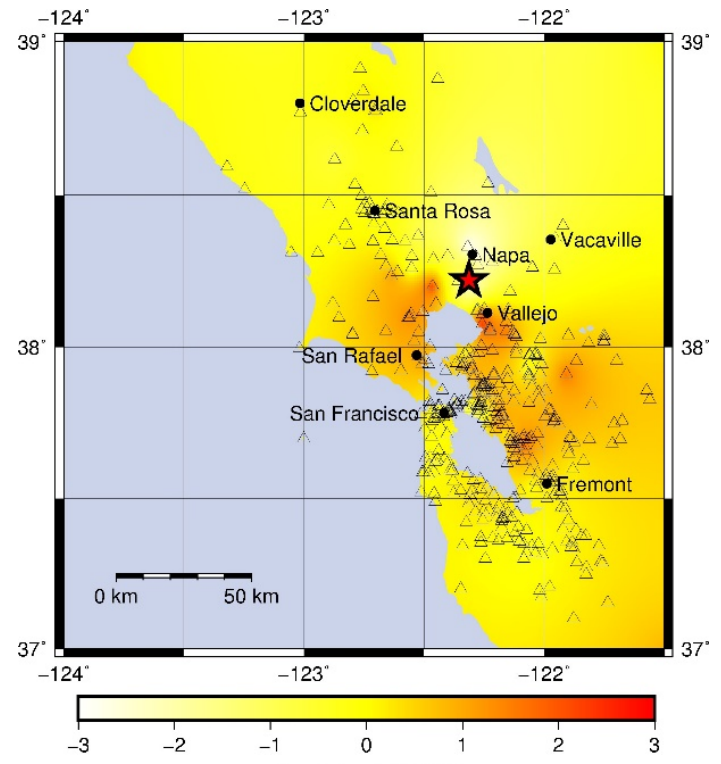

b).

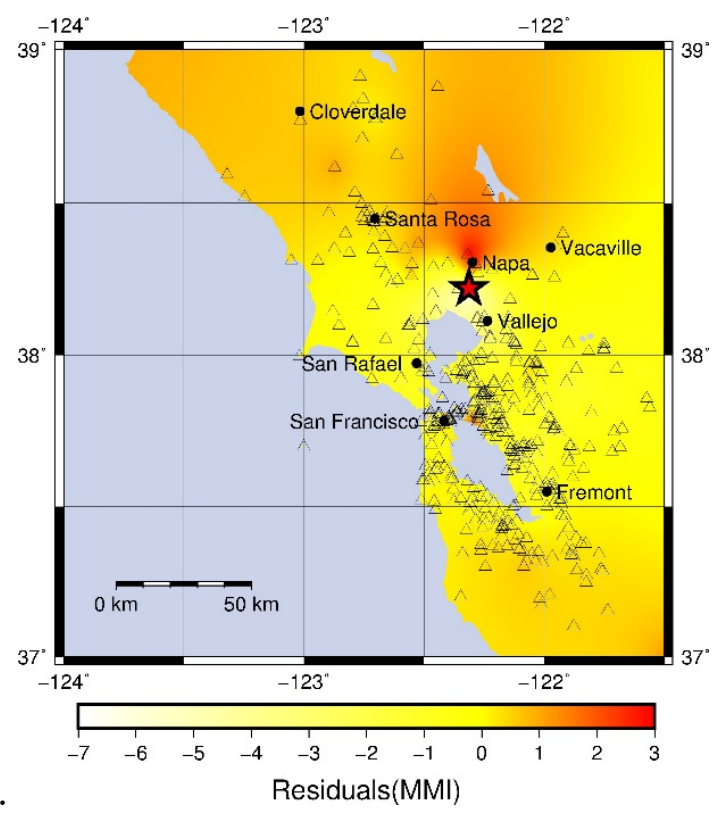

Figure 1. Ratio between combined intensity level (from physical and social sensors) and instrumental intensity level (triangles - seismic stations) after the Napa earthquake (red star epicenter): a) linear model, b) exponential model, c) two-segment model and d) three-segment 

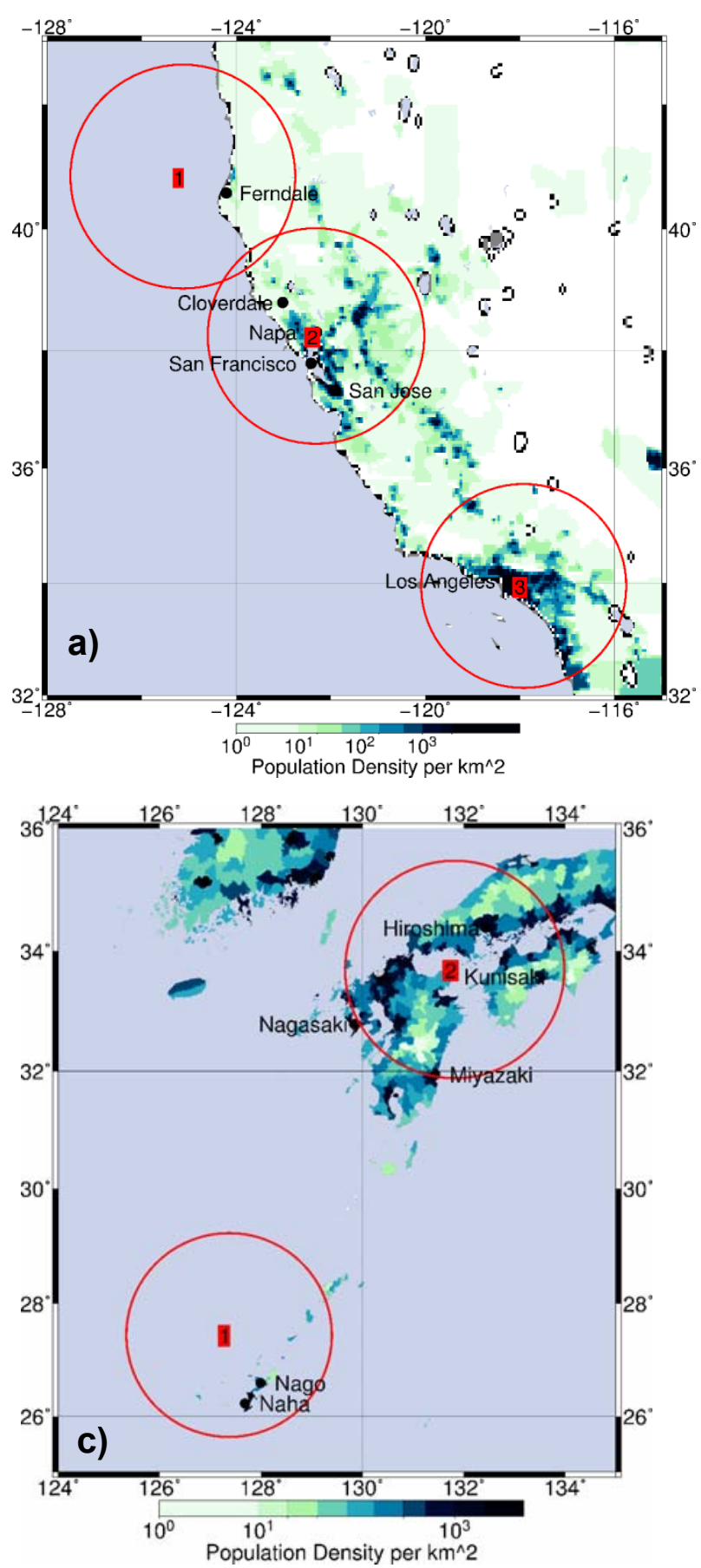

414

415

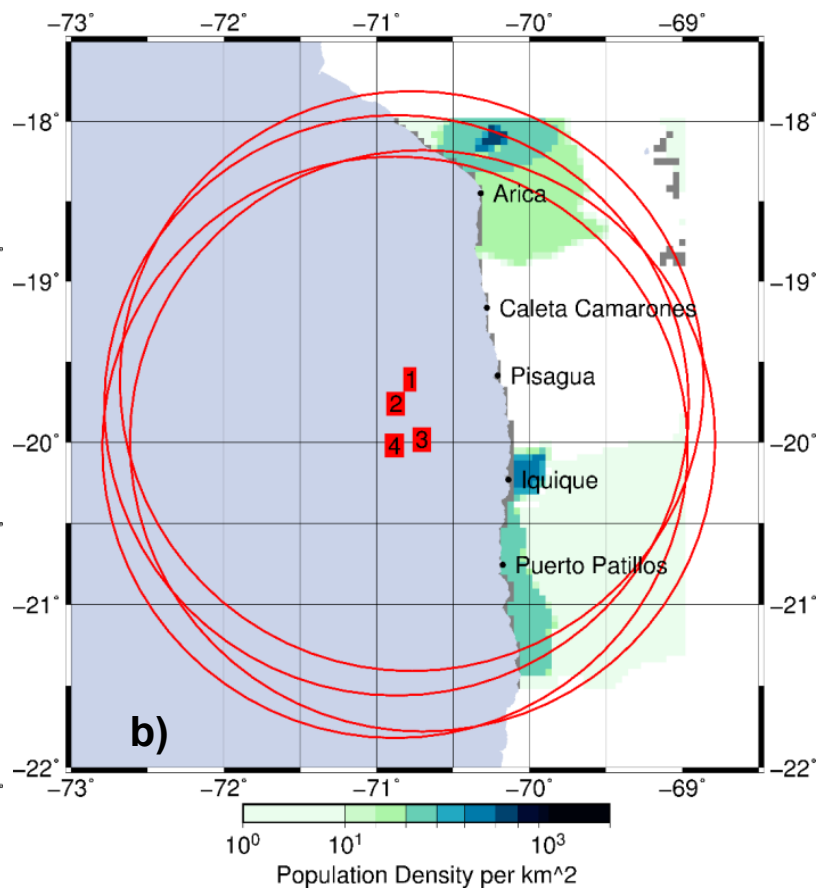

Figure 2. Population density in the regions with earthquake epicenters used in the validation and calibration process and areas covered for analysis (circles):

a - California ( 1 - Ferndale earthquake, 2 - Napa Valley earthquake, 3 - La Habra earthquake);

b - Chile (1 - 64km WNW of Iquique, 2 $80 \mathrm{~km}$ WNW of Iquique, $3-91 \mathrm{~km}$ WNW of Iquique, 4 - 94km NW of Iquique);

c - Japan (1 - Nago earthquake, 2 Kunisaki-shi).

(Population density data from GPWv3 (CIESIN, 2005)) 


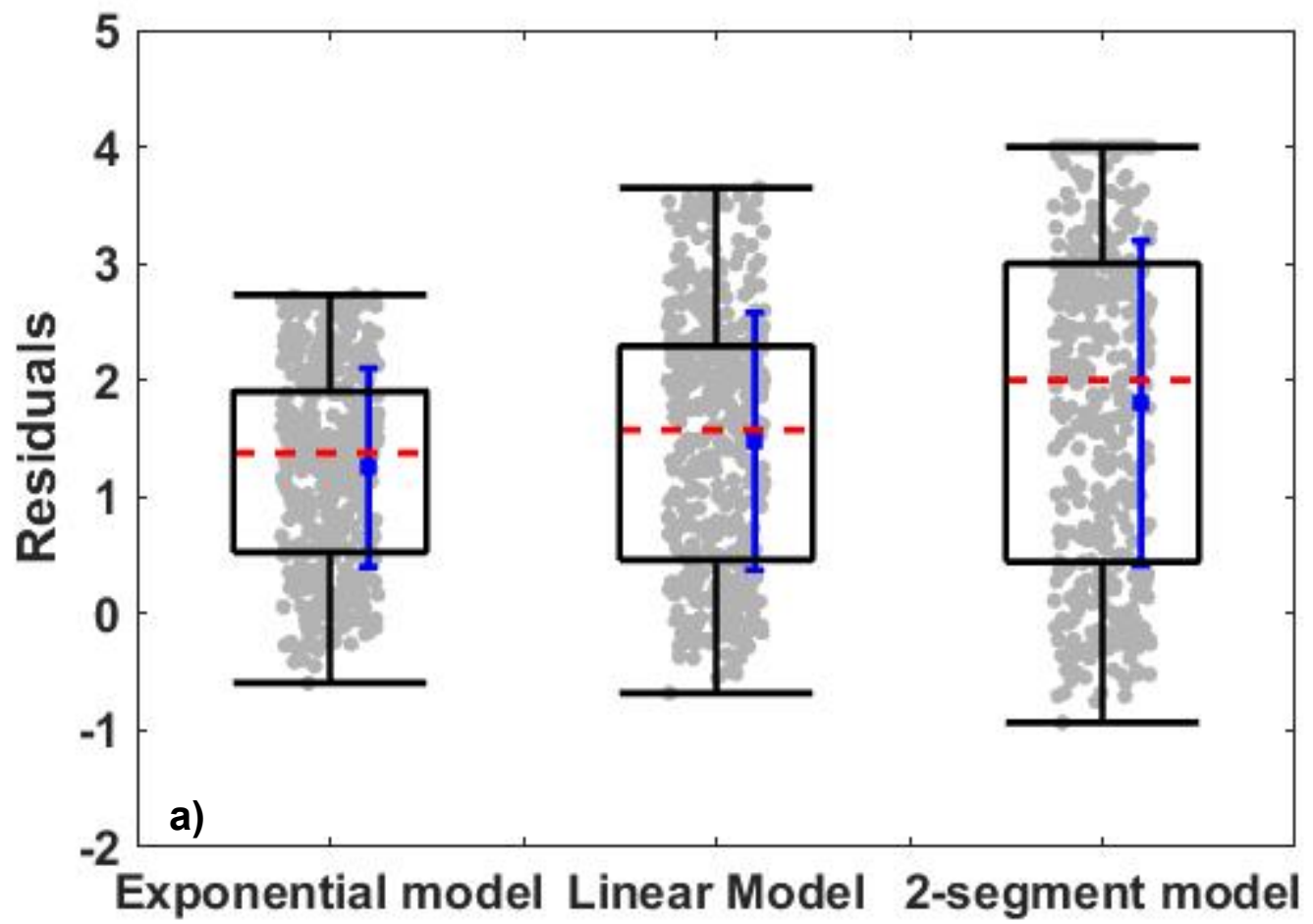

418

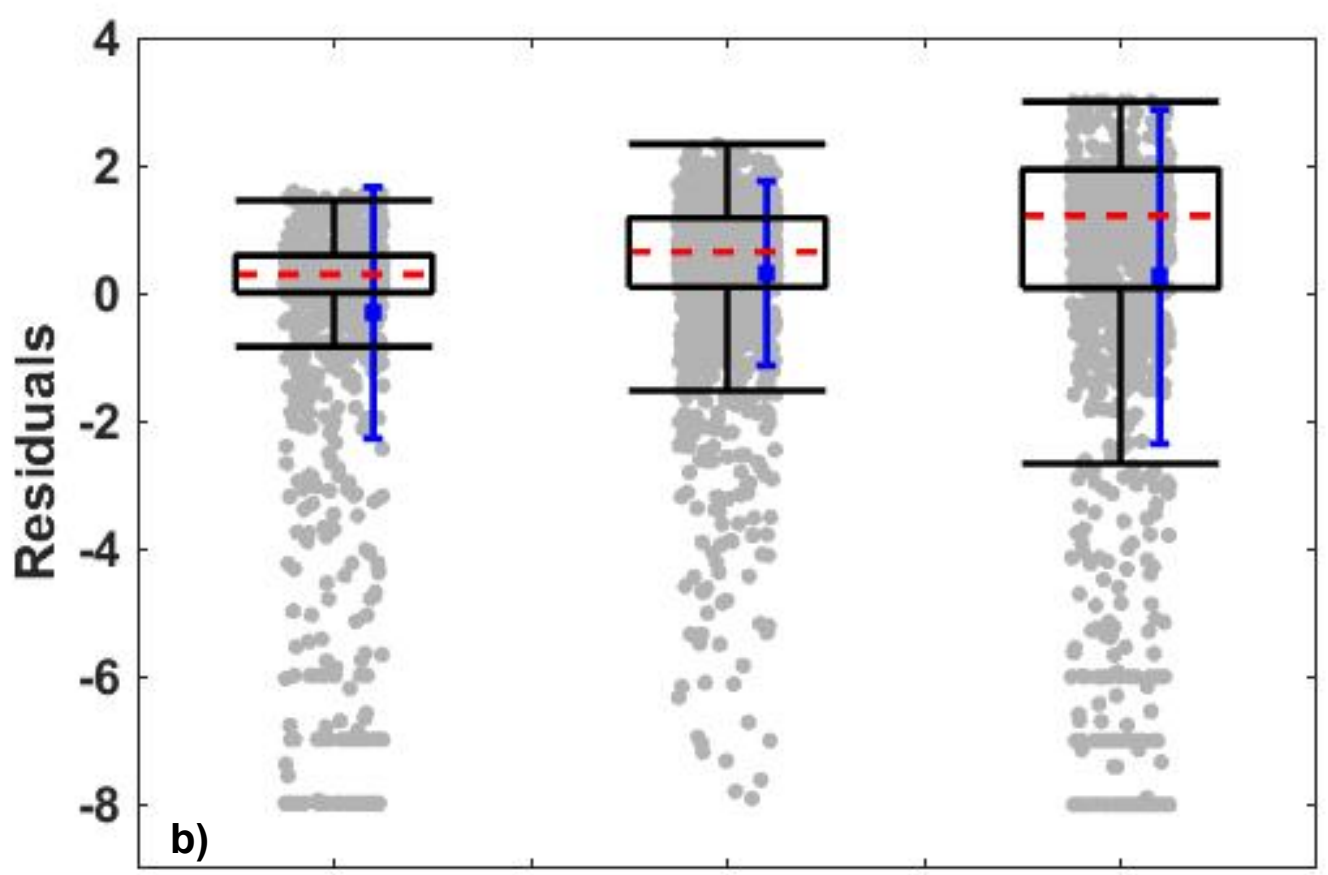

Exponential model Linear Model 2-segment model

420 Figure 3. Whisker diagram for the residuals (red - median, blue square - mean, error bars 421 standard deviation): a - Ferndale earthquake; b - La Habra earthquake. 

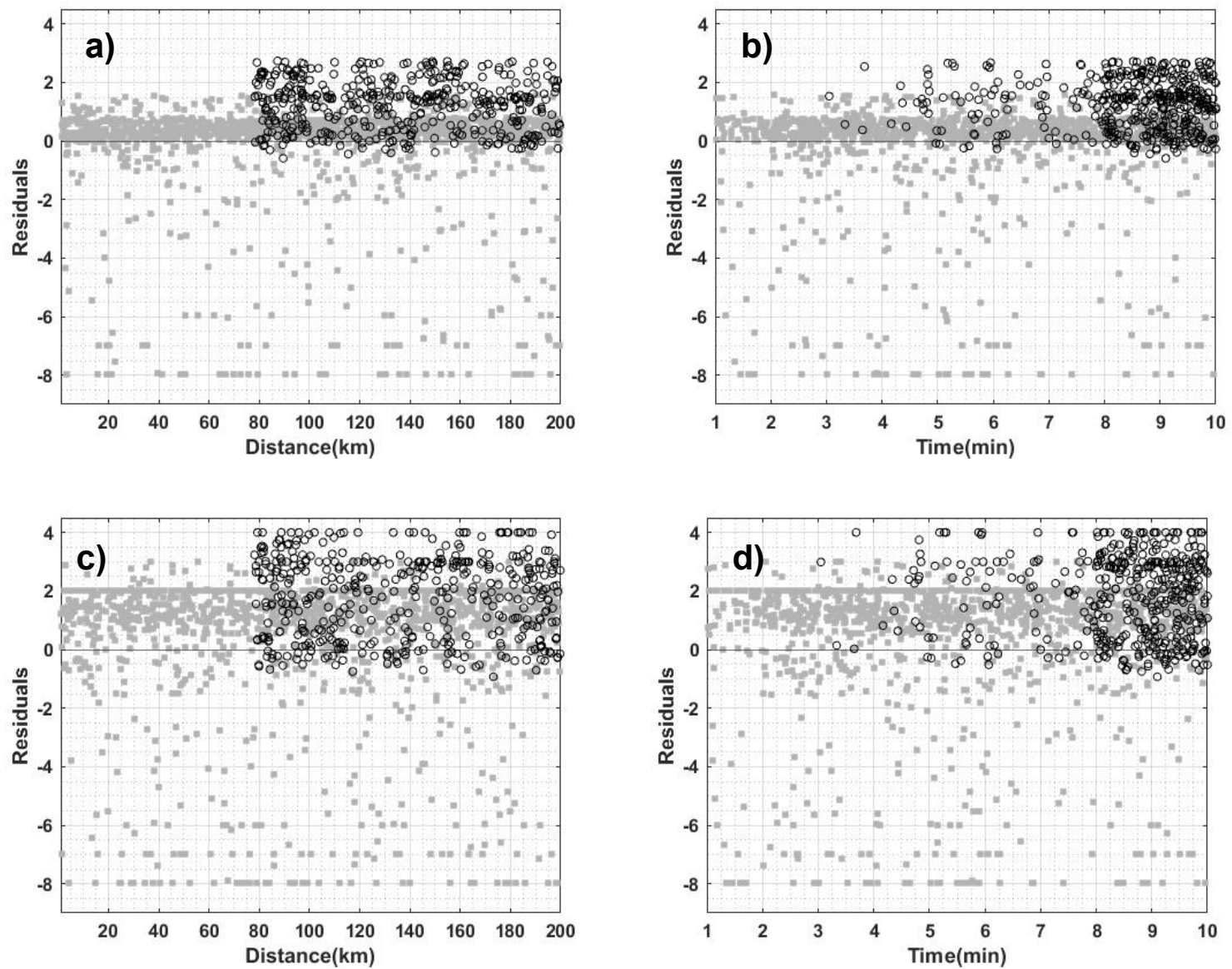

423
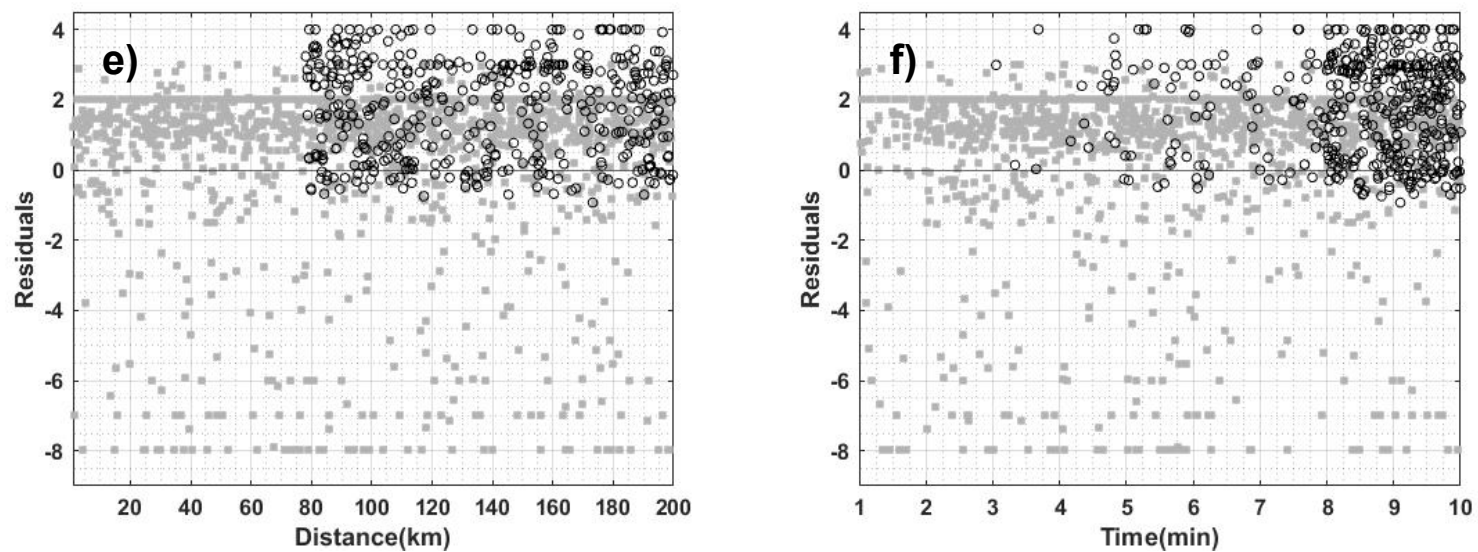

Figure 4 .Residuals vs. epicentral distance (a,c,e) and time (b,d,f) for the exponential (a, b), linear (c, d) two segment (e,f) models (grey squares - La Habra earthquake, black circles 427 Ferndale earthquake). 


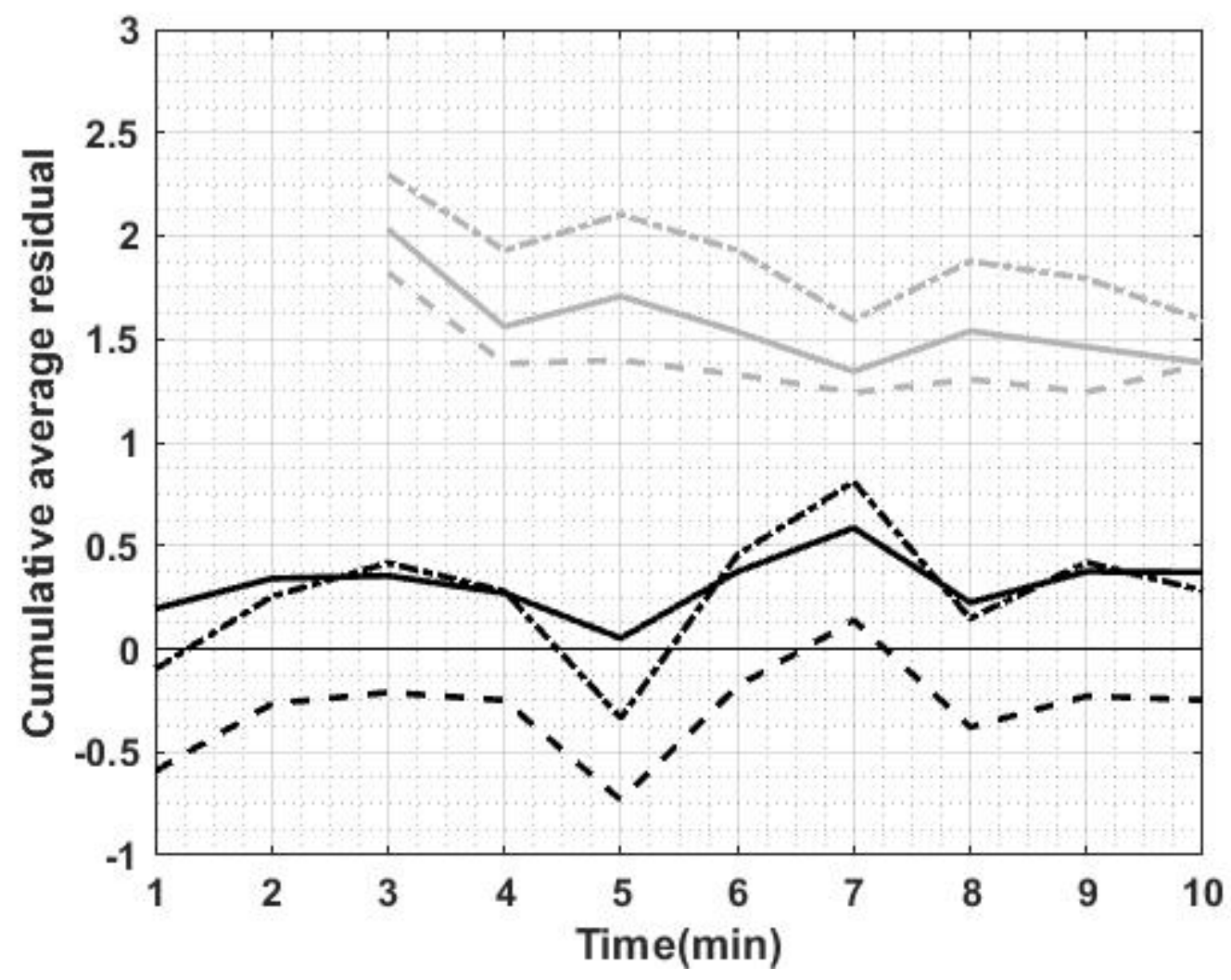

432 Figure 5. Cumulative average error over ten minutes (grey - Ferndale earthquake, black - La 433 Habra earthquake, solid line - linear model, dashed line - exponential model, dotted line - two434 segment linear model). 

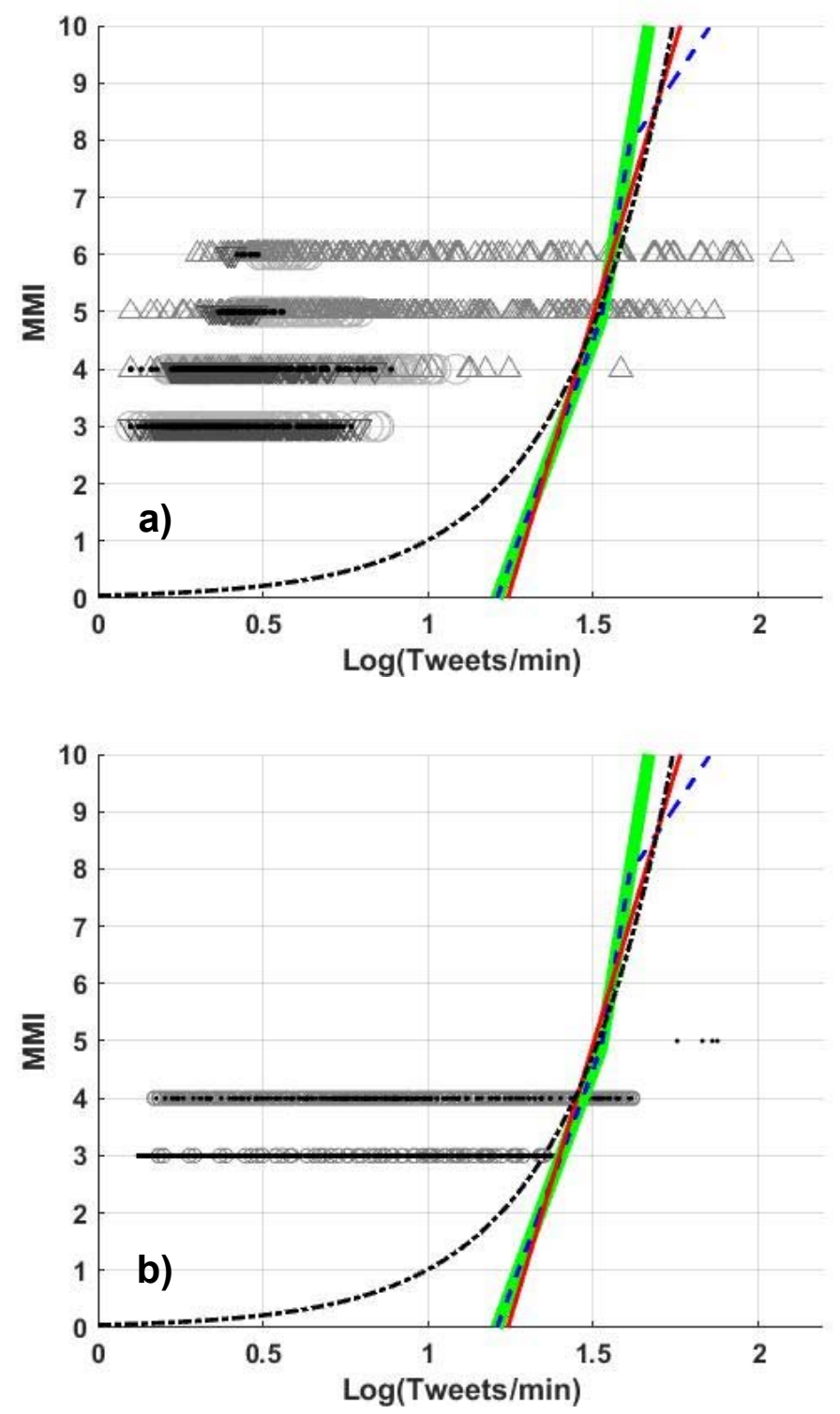

438 Figure 6. Observed earthquake data:

439

440

441

442

443

444

445

446 a) Chile (circles - $64 \mathrm{~km} \mathrm{WNW} \mathrm{of} \mathrm{Iquique,} \mathrm{upward} \mathrm{triangles} \mathrm{-} 80 \mathrm{~km}$ WNW of Iquique, downward triangles $-91 \mathrm{~km} \mathrm{WNW}$ of Iquique, dots $-94 \mathrm{~km} \mathrm{NW}$ of Iquique) with prediction models (solid thin line - linear, dot dashed line - exponential, thick solid line two-segment linear, dashed line - three segment);

b) Japan (circles - Nago earthquake, dots - Kunisaki-shi earthquake) with prediction models (solid thin line - linear, dot dashed line - exponential, thick solid line - two-segment linear, dashed line - three segment). 


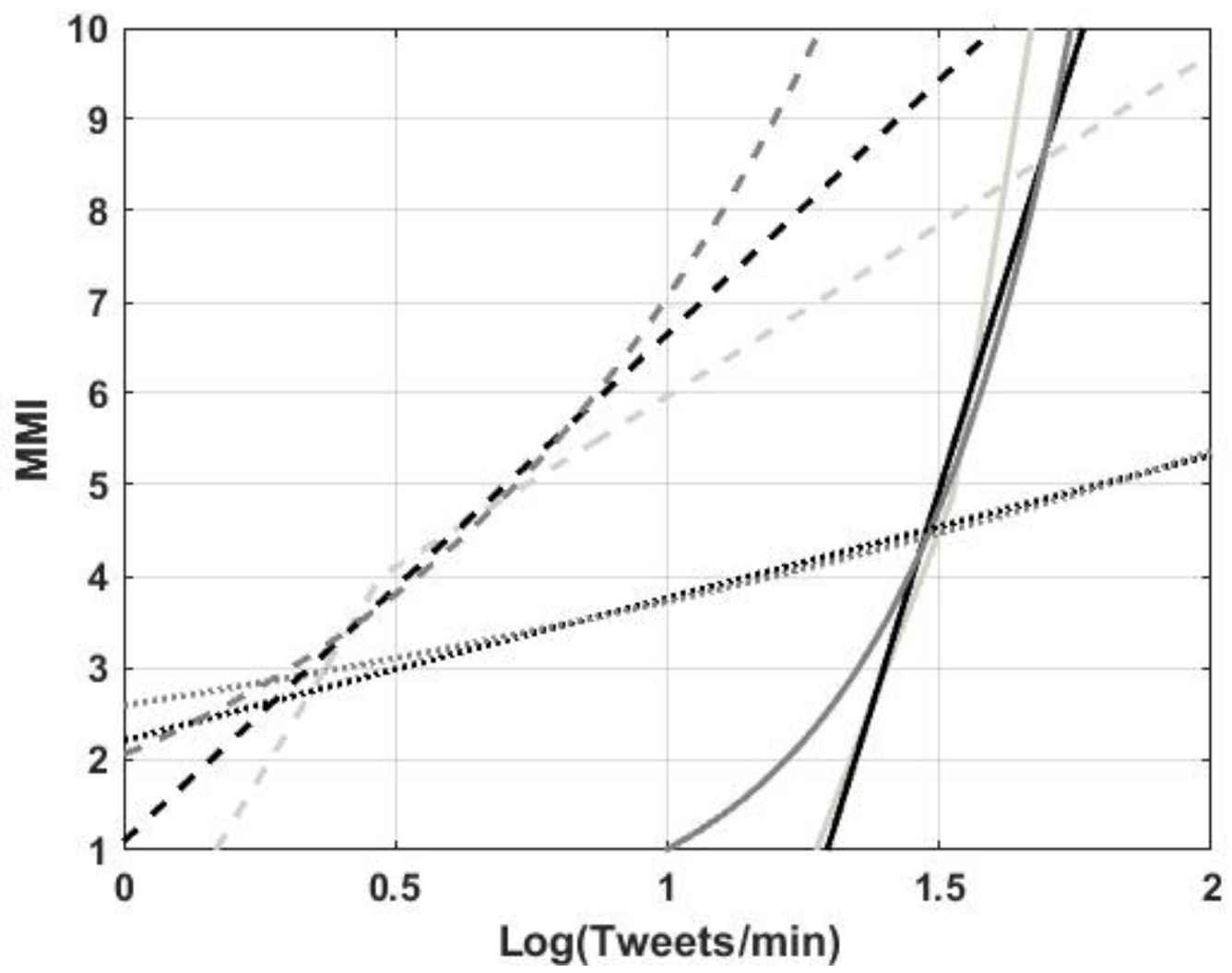

448 Figure 7. Calibrated models (black line - linear, dark grey line - exponential, light grey line 449 two-segment linear) for California (solid lines), Japan (dotted lines), Chile (dashed lines). 

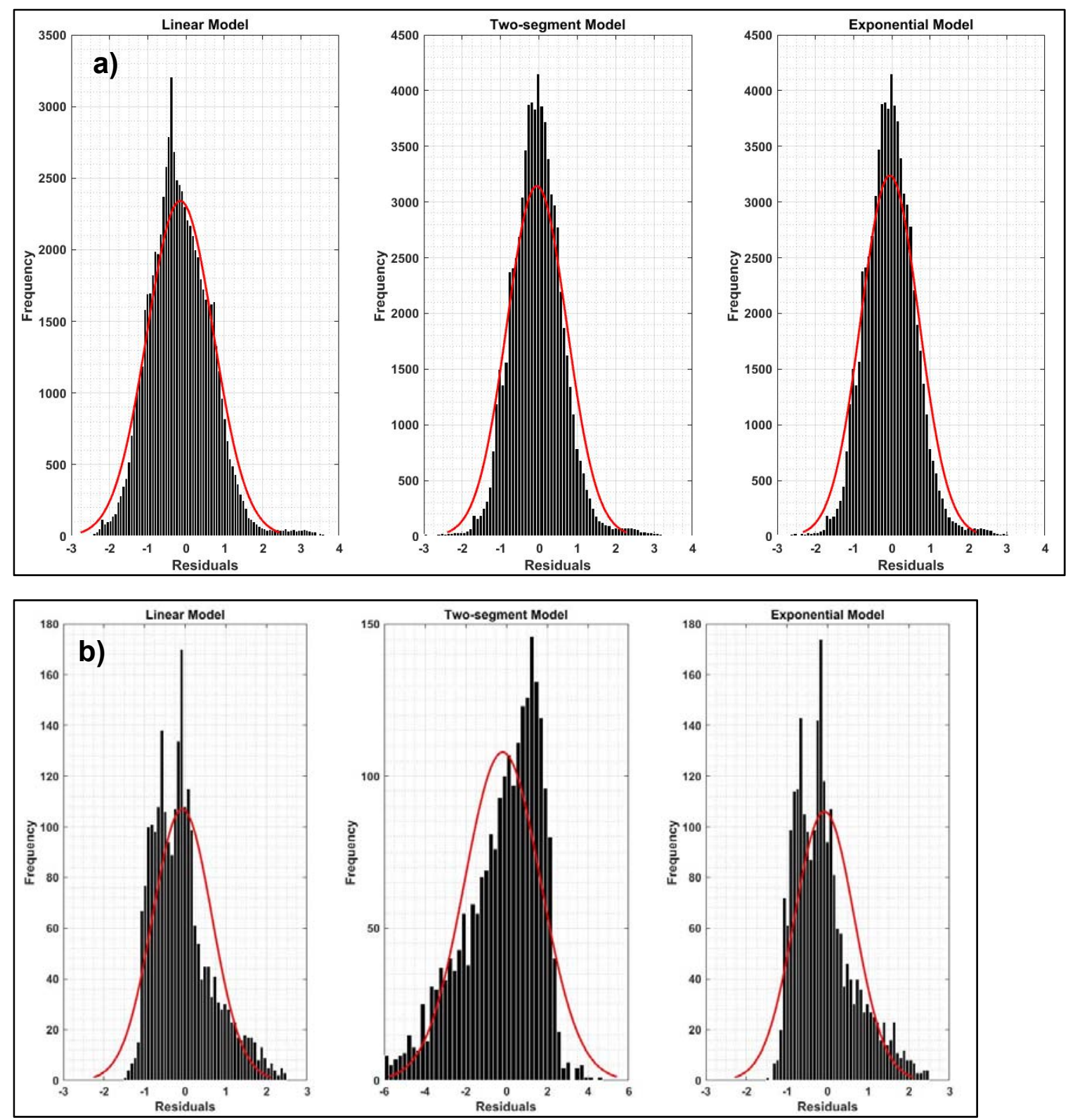

452
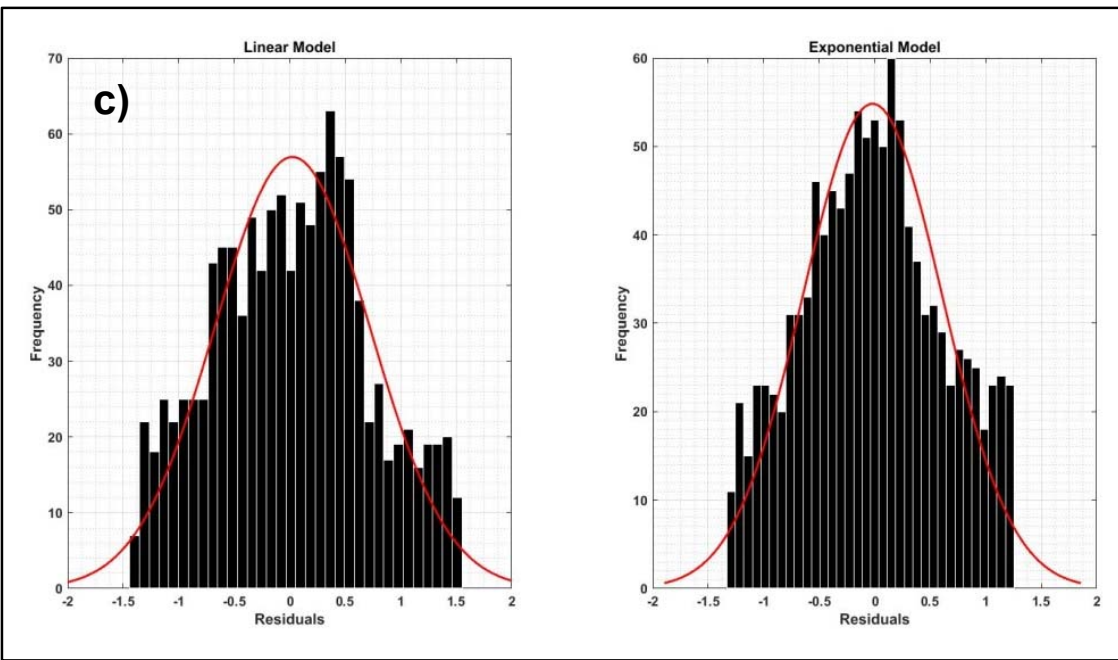

Figure 8. Residuals between calibrated models and observed data:
a). California
b). Chile
c) Japan 
454 Table 1. List of earthquakes used in validation and calibration processes

\begin{tabular}{|c|c|c|l|}
\hline Date and Time & Magnitude & $\begin{array}{r}\text { Depth } \\
(\mathrm{km})\end{array}$ & \multicolumn{1}{|c|}{ Epicenter Location } \\
\hline 2014-03-02 20:11 & 6.5 & 119 & $111 \mathrm{~km}$ NNW of Nago, Japan \\
\hline 2014-03-10 5:18 & 6.8 & 16.6 & $78 \mathrm{~km}$ WNW of Ferndale, California \\
\hline 2014-03-13 17:06 & 6.3 & 79 & $15 \mathrm{~km}$ NNE of Kunisaki-shi, Japan \\
\hline 2014-03-16 21:16 & 6.7 & 20 & $64 \mathrm{~km}$ WNW of Iquique, Chile \\
\hline 2014-03-17 5:11 & 6.4 & 21 & $80 \mathrm{~km}$ WNW of Iquique, Chile \\
\hline 2014-03-22 12:59 & 6.2 & 20 & $91 \mathrm{~km}$ WNW of Iquique, Chile \\
\hline 2014-03-29 4:09 & 5.1 & 5.1 & $2 \mathrm{~km}$ E of La Habra, California \\
\hline 2014-04-01 23:46 & 8.2 & 25 & $94 \mathrm{~km}$ NW of Iquique, Chile \\
\hline
\end{tabular}


457 Table 2. Calibrated Predictive Relationships

\begin{tabular}{|c|c|c|c|}
\hline Model Name & Equation & $\begin{array}{l}\text { RMS error, } \\
\text { MMI units }\end{array}$ & $\begin{array}{c}\text { Valid range of } \\
\text { values } \\
\text { (Ntweets/min) }\end{array}$ \\
\hline \multicolumn{4}{|c|}{ California } \\
\hline Linear & MMI $=19.11 * \log ($ Ntweets $/ \min )-23.72$ & 0.0033 & {$[17.43 ; 58.15]$} \\
\hline Exponential & $\begin{array}{c}\mathrm{MMI}=0.04636^{*} \exp \left(3.086^{*}\right. \\
\log (\text { Ntweets } / \mathrm{min}))\end{array}$ & 0.0035 & $(0 ; 55.1]$ \\
\hline $\begin{array}{l}\text { Two-segment } \\
\text { linear }\end{array}$ & $\begin{array}{c}\mathrm{MMI}=15.41 * \log (\text { Ntweets } / \min )-18.63 \\
\log (\text { Ntweets } / \min )<1.52 \\
\text { MMI }=35.47 * \log (\text { Ntweets } / \min )-49.19 \\
1.52<\log (\text { Ntweets } / \mathrm{min})<1.61\end{array}$ & 0.0029 & {$[24.4 ; 46.63]$} \\
\hline \multicolumn{4}{|c|}{ Japan } \\
\hline Linear & $\mathrm{MMI}=1.56 * \log ($ Ntweets $/ \mathrm{min})+2.2$ & 0.0207 & {$\left[0.04 ; 10^{5}\right]$} \\
\hline Exponential & $\begin{array}{c}\mathrm{MMI}=2.584 * \exp \left(0.3653^{*}\right. \\
\log (\text { Ntweets } / \mathrm{min}))\end{array}$ & 0.0186 & $(0 ; 5064]$ \\
\hline \multicolumn{4}{|c|}{ Chile } \\
\hline Linear & $\mathrm{MMI}=1.58 * \log ($ Ntweets $/ \mathrm{min})+3.241$ & 0.0143 & {$[0.009 ; 18960]$} \\
\hline Exponential & $\mathrm{MMI}=3.4^{*} \exp \left(0.339^{*} \log (\right.$ Ntweets $\left./ \mathrm{min})\right)$ & 0.0145 & $(0 ; 1517.6]$ \\
\hline $\begin{array}{l}\text { Two-segment } \\
\text { linear }\end{array}$ & $\begin{array}{c}\text { MMI }=16.06 * \log (\text { Ntweets } / \mathrm{min})-3.5338 \\
\log (\text { Ntweets } / \text { min })<0.47 \\
\text { MMI }=3.59 * \log (\text { Ntweets } / \mathrm{min})+2.32 \\
1.52<\log (\text { Ntweets } / \mathrm{min})<0.86\end{array}$ & 0.0358 & {$[1.66 ; 137.8]$} \\
\hline
\end{tabular}

